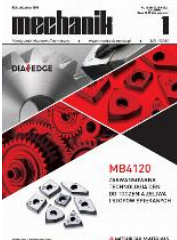

\title{
Measurements and analysis size of abrasive micrograins
}

\section{ADAM BARYLSKI *}

Prof. dr hab. inż. Adam Barylski, prof. zw., abarylsk@pg.edu.pl, https://orcid.org/0000-0003-1672-8445 - Wydział Mechaniczny Politechniki Gdańskiej

The paper discussed automated size and shape analysis of both abrasive grains and micrograins. In research on micrograins of boron carbide, silicon carbide, ordinary and noble electrocorundum stereoscopic optical microscopy was applied and MultiScan software solutions were used.

KEYWORDS: abrasive micrograins, size, shape, analysis

\section{Introduction}

Properties of abrasive grains and micrograins, tested at various stages of their production and subsequent use (e.g. for pre-treatment, finishing or very accurate), are criteria for assessing their quality [1]. Five groups of determined grain properties can be distinguished $[5-7,9-12,29,30]$ :

- properties determined for the whole set (including type, dimensions and shape of grains, abrasive wettability, bulk density, magnetic fraction content),

- technological indicators (color, sinterability),

- physicochemical surface properties $(\mathrm{pH})$,

- chemical and structural properties (chemical composition, microstructure),

- mechanical and operational properties (hardness, compressive strength, wear resistance, abrasive properties).

In finishing and very precise machining, the stereometry of grains and micrograins is very important [3]. Irregular shapes of the abrasive micrograins cause difficulties in determining their size (fig. 1). For this reason, different grain sizes are usually determined: average, statistical or equivalent.

a)

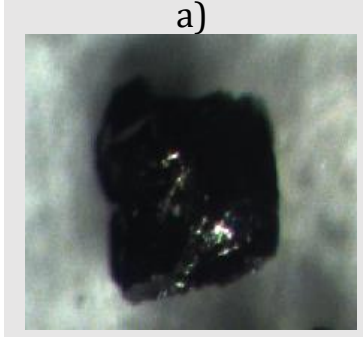

d)

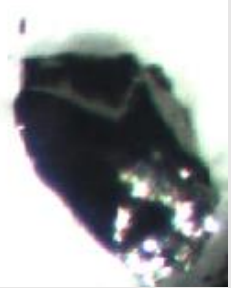

b)

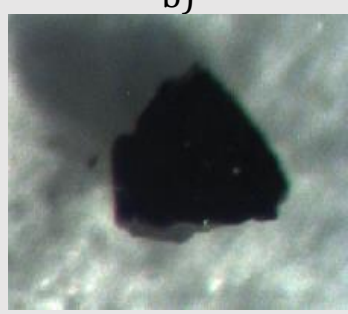

e)

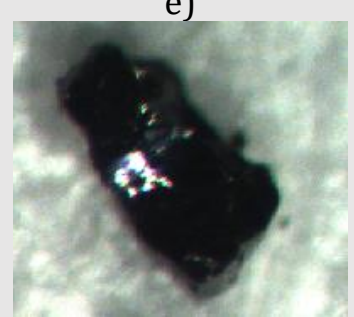

c)

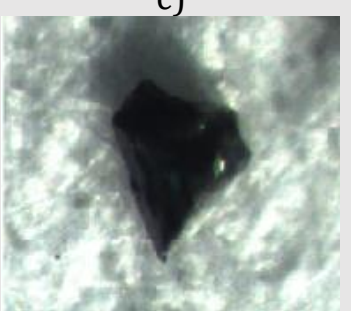

f)

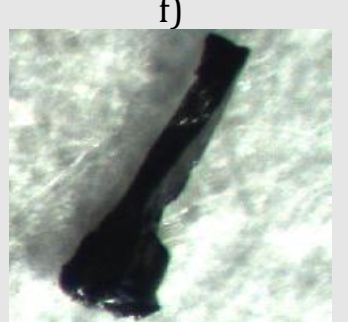

Fig. 1. The most commonly classified shapes of abrasive micrograins: a) isometric,

b) lamellar, c) lamellar, d) pillar-shaped, e) dermoid, f) coniferous

Each grain can have three basic dimensions:

- length $l$,

- width $b$,

- height $h$ - as dimensions of the smallest cuboid described on the grain. 
The average grain size can be determined by sieve analysis, and statistical one - e.g. by microscopic analysis.

An equivalent dimension may be the diameter of a ball, the volume or surface of which corresponds to the volume or surface of the grain.

Since the dimensions of abrasive grains can be determined by different methods, information on which measurement method was used in a given case should be always provided [2, 4]. For larger grains, sieve methods are usually used, and for finer grains - sedimentation, laser and microscopic methods [13, 14, 16-28].

In the preparation of abrasive suspensions or pastes for the lapping and polishing operations are applied, among others, stereoscopic microscopy. Merck Millipore developed the standard microscopic methodology by combining an optical microscope with a CCD camera and a computer. Specialist software has also been developed since then.

This paper deals with the measurement and analysis - using a computerized stereoscopic microscope - of the sizes of selected abrasive micrograins intended for very accurate machining.

\section{Measurement stand and research methodology}

Figure 2 presents a general view of the measuring station.

In tab. I, types of tested abrasive micrograins were summarized [8]. In order to determine the minimum number $\mathrm{n}$ of individual experiments after the initial test, the relationship was used:

$$
n \geq\left(\mu_{\alpha} \cdot \frac{s}{d}\right)^{2}
$$

where: $\mu_{\alpha}$ - critical value from the t-Student's distribution table $\left(\mu_{\alpha}=2.046\right.$ for significance level $\left.\alpha=0.05\right)$, $s$-standard deviation determined in the initial test [ $\mu \mathrm{m}], d$ - assumed error of measurement [ $\mu \mathrm{m}]$ (tab. II).

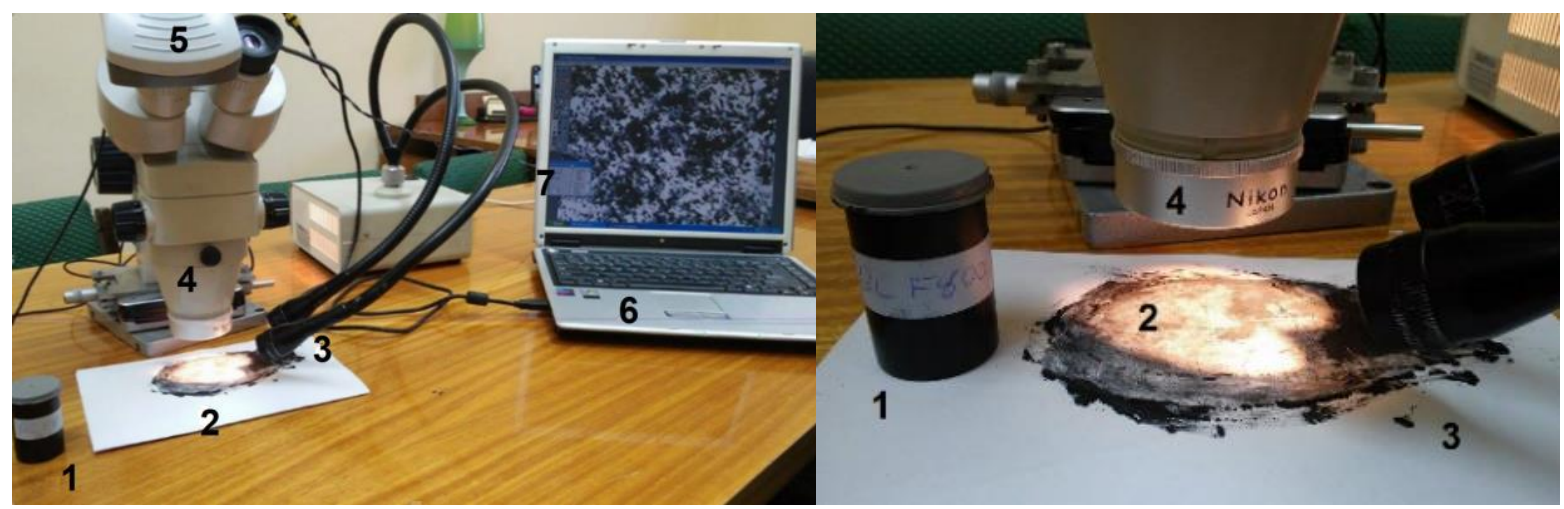

Fig. 2. General view of the station for measuring the size of abrasive micrograins. Designations:

1 - abrasive container (test sample), 2 - set of micrograins scattered in a single layer on the observation plane (dose tested), 3 - two-arm halogen illuminator, 4 - Nikon stereoscopic microscope, 5 - CCD camera, 6 - computer, 7 - MultiScan software

TABLE I. Tested abrasive micrograins

\begin{tabular}{|c|c|c|}
\hline Abrasive grade & Designation & Medium normative dimension [ $\mu \mathrm{m}]$ \\
\hline Boron carbide & BC F320 & 29 \\
\hline Boron carbide & BC F600 & 9 \\
\hline Boron carbide & BC F800 & 7 \\
\hline Black silicon carbide & 98C F400 & 17 \\
\hline Green silicon carbide & 99C F400 & 17 \\
\hline Normal aluminum oxide & 95A F400 & 17 \\
\hline Normal aluminum oxide & 95A F500 & 17 \\
\hline Normal aluminum oxide & 95A F400 & 17 \\
\hline Noble electrocorundum & 99A F400 & \\
\hline
\end{tabular}

TABLE II. Values of permissible measurement error

\begin{tabular}{|l|c|c|c|c|c|}
\hline Normative micrograin size & F320 & F400 & F500 & F600 & F800 \\
\hline Measurement error $d[\mu \mathrm{m}]$ & 25 & 1.5 & 1 & 0.8 & 0.6 \\
\hline
\end{tabular}


In tab. III, the specified minimum numbers of main samples are given (in individual experiments).

Figure 3 illustrates the method of measuring individual micrograins. Using the MultiScan v. 6.08 program, the length $l$, width $b$ and the $A$ surface area were measured for a randomly selected batch of micrograins, projected on a plane parallel to the observation surface.

TABLE III. minimum number of samples of micrograins tested

\begin{tabular}{|c|c|c|c|}
\hline $\begin{array}{c}\text { Micrograins } \\
\text { tested }\end{array}$ & $\begin{array}{c}\text { Preliminary } \\
\text { sample count }\end{array}$ & $\begin{array}{c}\text { Standard deviation } \\
\text { in the initial sample } s[\mu \mathrm{m}]\end{array}$ & $\begin{array}{c}\text { Minimum sample size } \\
\text { of the main sample }\end{array}$ \\
\hline BC F320 & 30 & 58.01 & 23 \\
\hline BC F600 & 30 & 2.12 & 30 \\
\hline BC F600 & 30 & 1.49 & 26 \\
\hline 98C F400 & 30 & 3.45 & 11 \\
\hline 99C F400 & 30 & 5.75 & 29 \\
\hline 95A F400 & 30 & 3.14 & 9 \\
\hline 95A F500 & 30 & 1.99 & 17 \\
\hline 95A F600 & 30 & 2.08 & 29 \\
\hline 99A F400 & 30 & 2.48 & 6 \\
\hline
\end{tabular}

a)

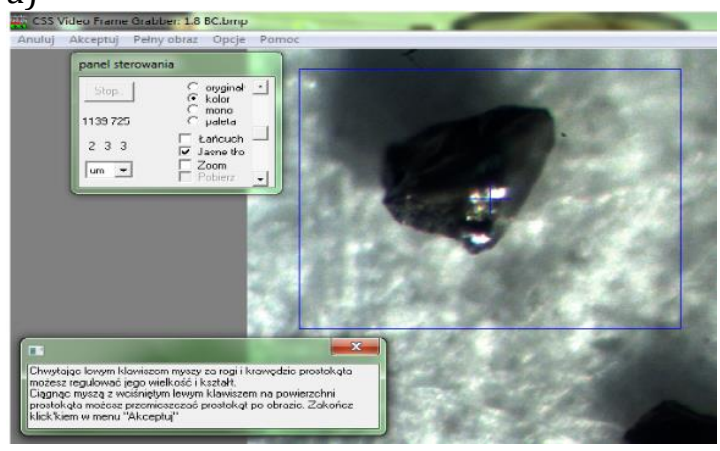

b)

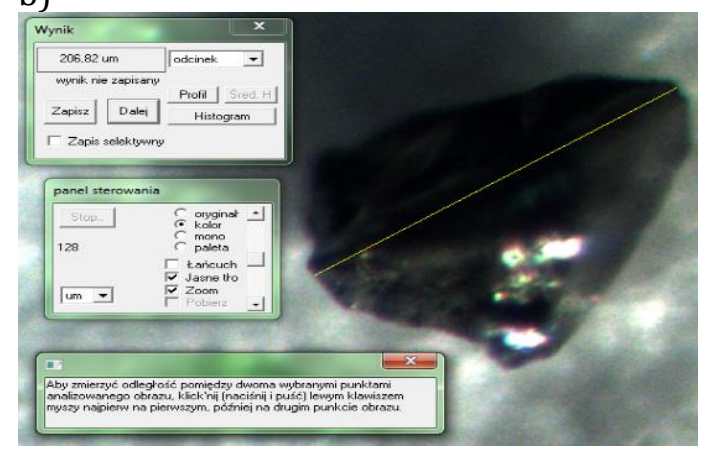

Fig. 3. Screen photos: a) micrograin selection, b) measured abrasive micrograin

\section{Measurement results}

Figs. 4-7 show examples of measured geometrical parameters of the abrasive micrograins of boron carbide, silicon carbide and alumina.
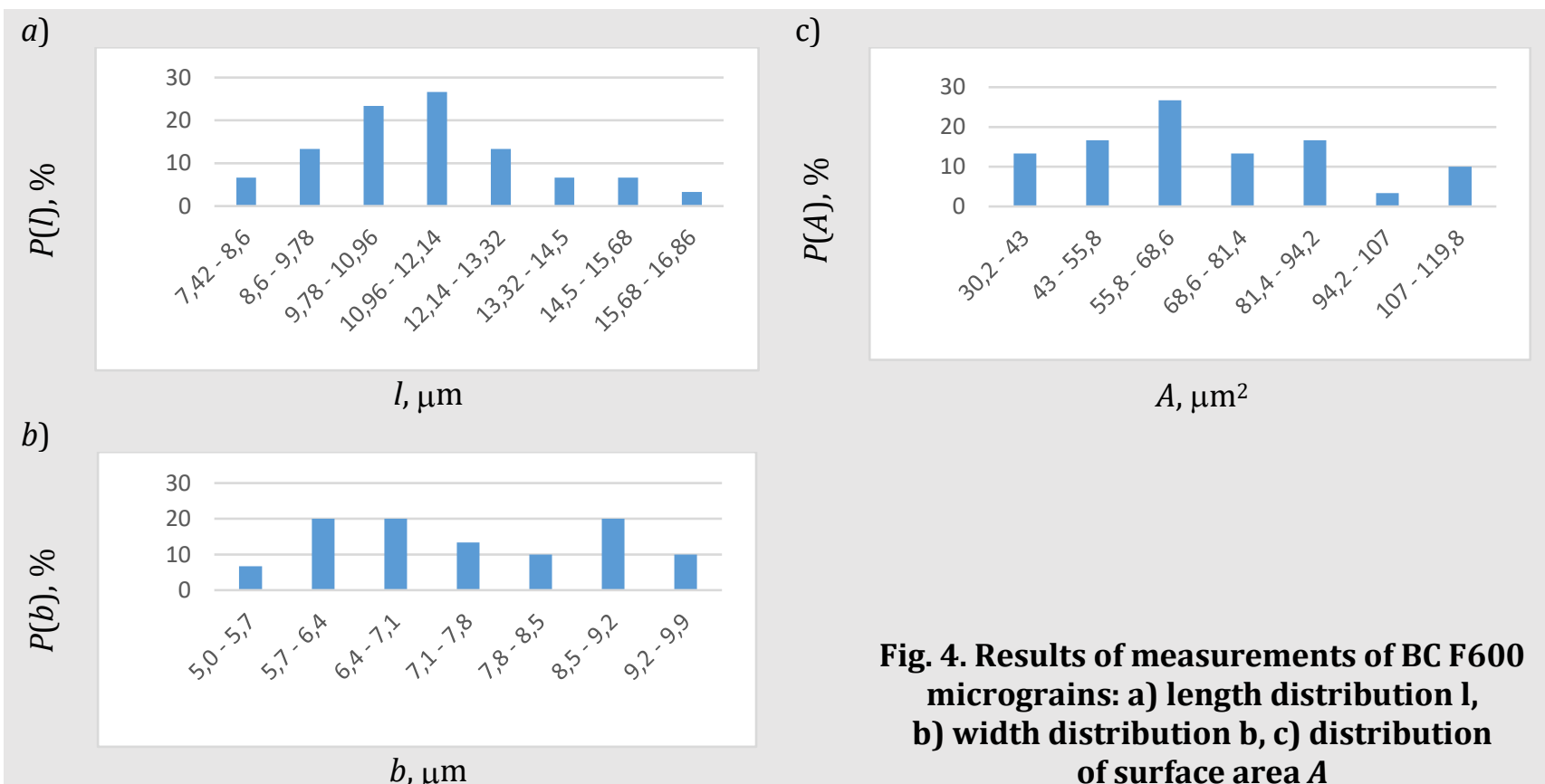

Fig. 4. Results of measurements of BC F600 micrograins: a) length distribution $l$, b) width distribution $b$, c) distribution of surface area $A$ 

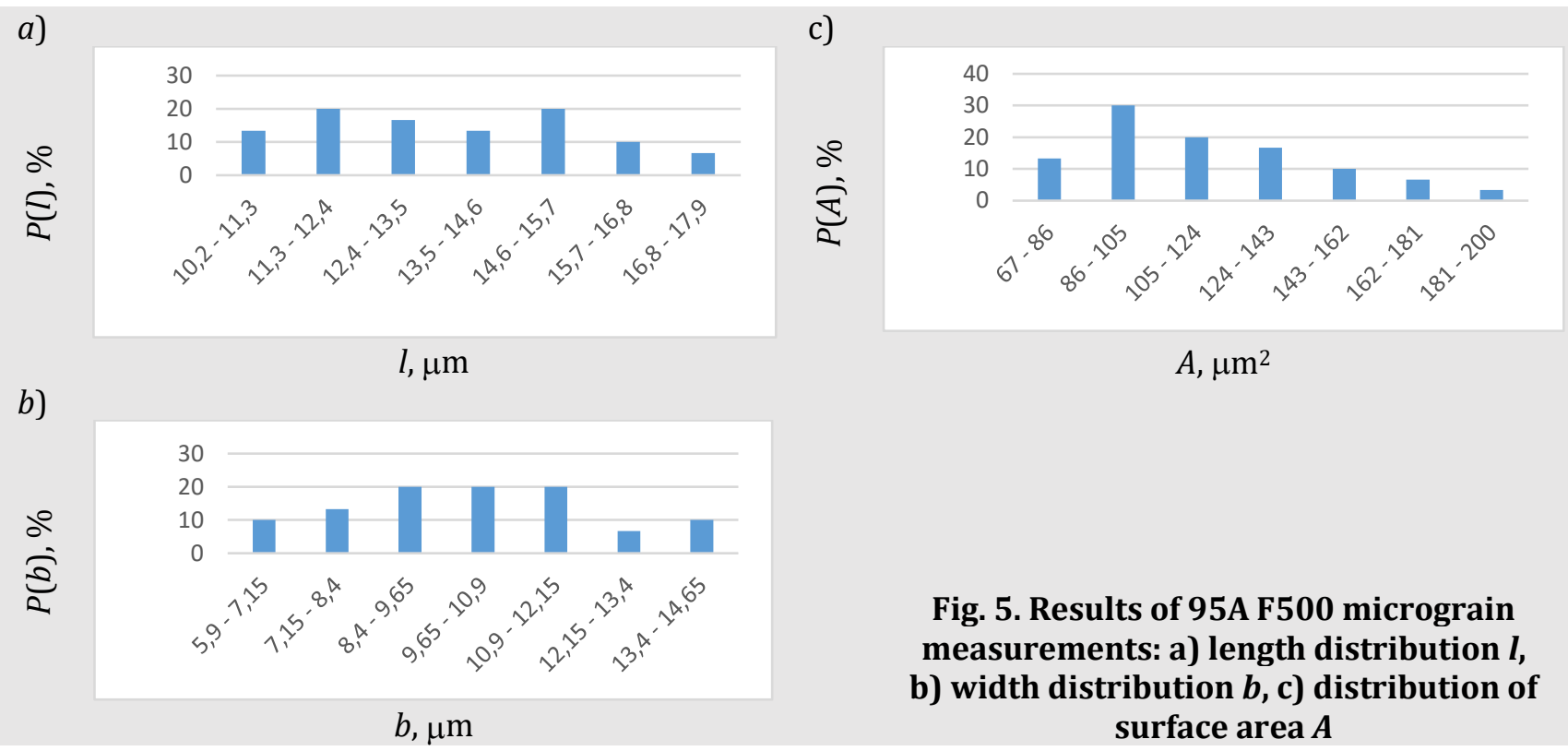

$$
\text { A, } \mu \mathrm{m}^{2}
$$

Fig. 5. Results of 95A F500 micrograin measurements: a) length distribution $l$, b) width distribution $b, c)$ distribution of surface area $A$
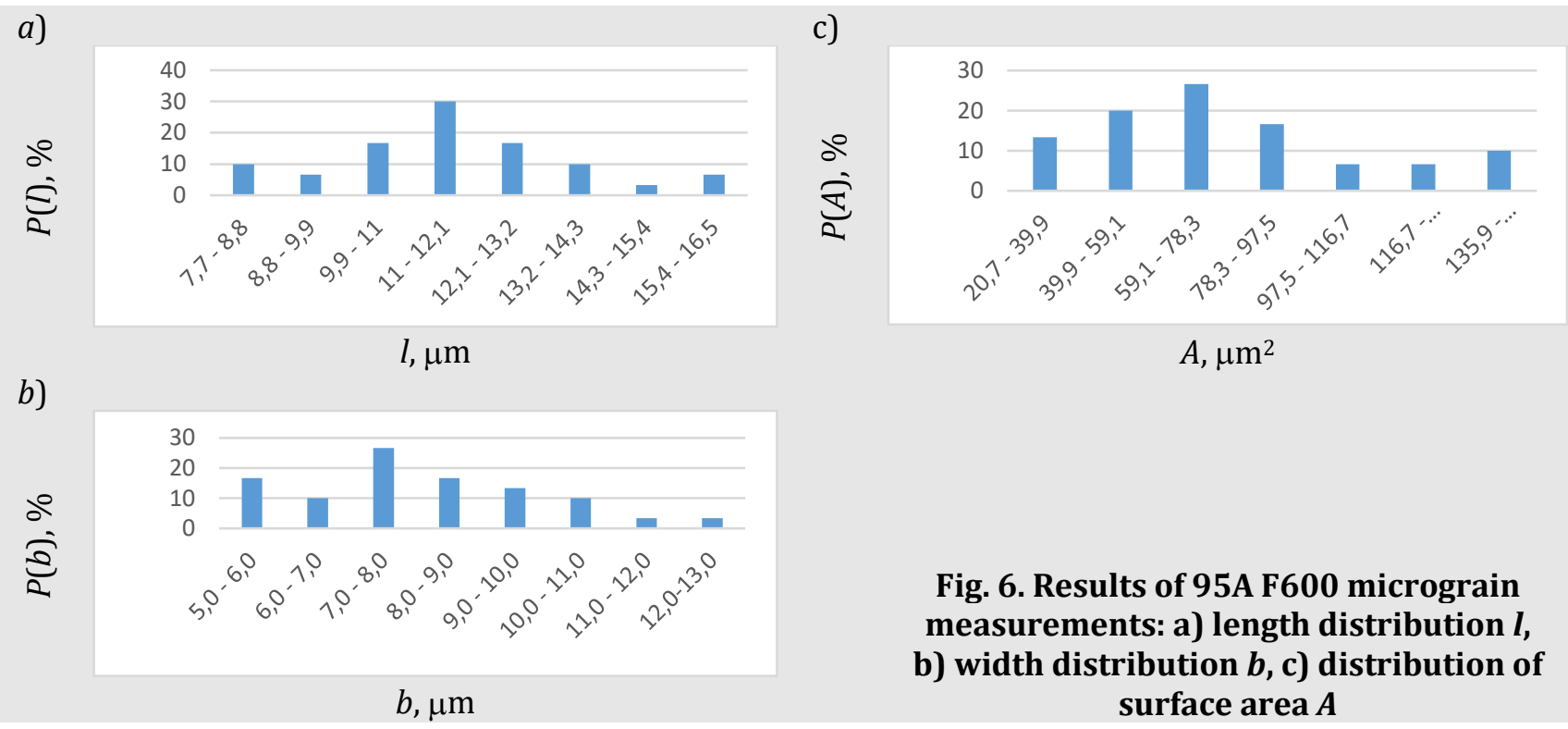

Fig. 6. Results of 95A F600 micrograin measurements: a) length distribution $l$, b) width distribution $b$, c) distribution of
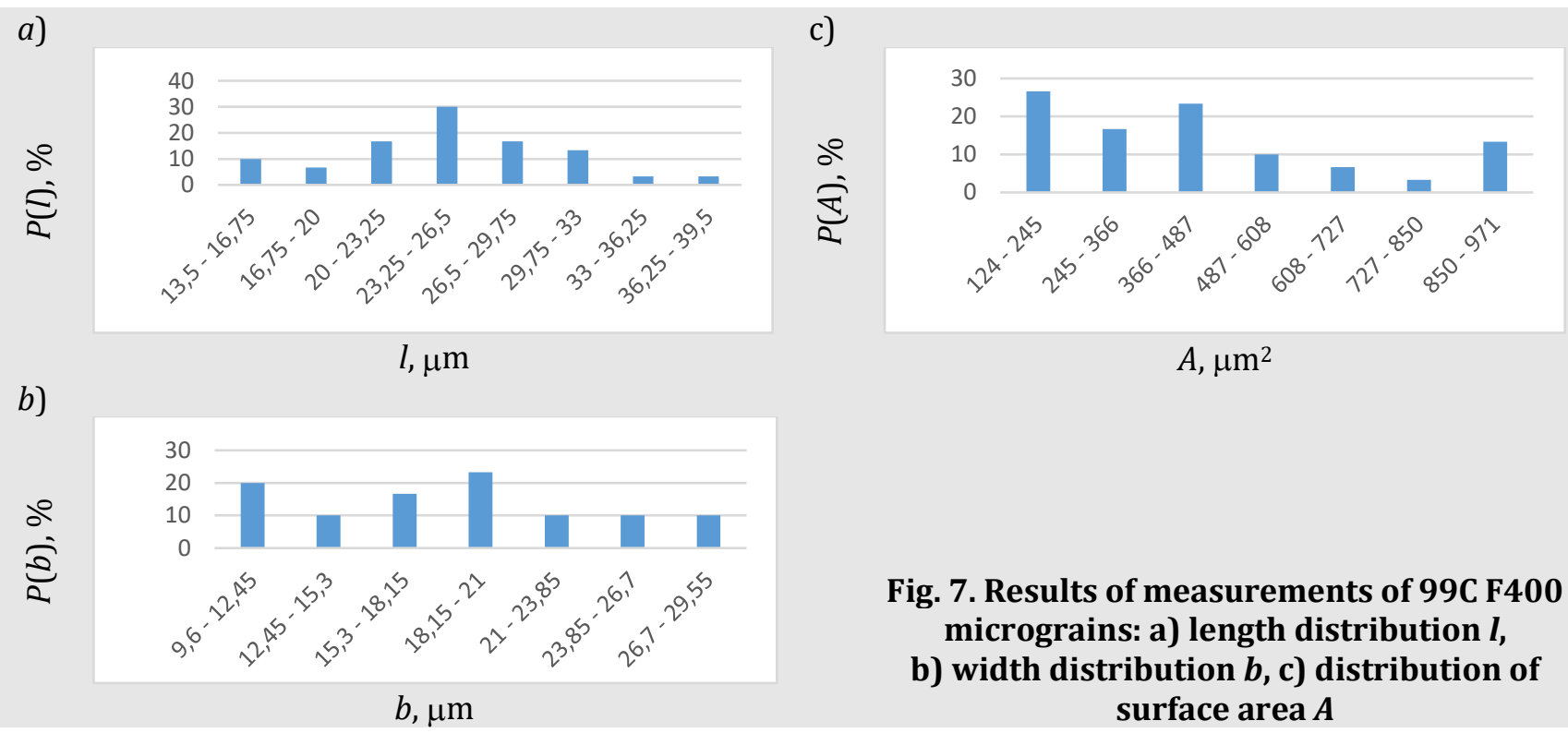

Fig. 7. Results of measurements of 99C F400 micrograins: a) length distribution $l$, b) width distribution $b, c)$ distribution of surface area $A$ 
After analyzing the obtained $l$-length distributions, it was found that larger micrograins of boron carbide (F320 and F600) had negative asymmetry, and the micrograins F800 - positive asymmetry. On the other hand, for the width b of micrograins, positive asymmetry characterizes F320 micrograins, while the remaining ones have negative asymmetry. In the case of the tested surface area $A$, all samples are characterized by distribution with right-sided positive asymmetry. For each of the analyzed geometric parameters, the obtained empirical distributions have a negative excess, which indicates the occurrence of flattened distributions. The average shape coefficients $K=l / b$ of the tested micrograins are similar and are: $K=1.52$ (BC F320), $K=1.54$ (BC F600) and $K=1.39$ (BC F800), respectively. Slight differences were found between the length 1 of F600 and F800 micrograins and normative values (PN-ISO 8486-2) of the average characteristic grain size.

Based on the comparison of the obtained statistical distributions, it was found that the length distributions I of micrograins 95A and 99A with the same normative number F400 have negative asymmetry, and the width distances $b$ and the area of projections $A$ - positive asymmetry. The analyzed 95A F500 abrasive is characterized by the lack of asymmetry in the length distribution $l$; the width distribution $b$ has negative asymmetry, and the area of $A$ has positive asymmetry. In the case of the 95A F600 micrograins, all the distributions obtained had positive asymmetry and were flattened, as evidenced by the negative value of excesses. The average shape coefficients of the micrograins 99A F400 and 95A F400 are almost identical and are: $K=1.51$ and $K=1.53$, respectively. The shape coefficients of the smallest micrograins of ordinary corundum tested are also similar: $K=1.36$ for $95 \mathrm{~F} 500$ and $K=1.42$ for $95 \mathrm{~A} \mathrm{~F} 600$. Taking into account the results of the analysis, it was found that the fine grains of fine aluminum oxide F400 and ordinary aluminum oxide F500 have an average grain image length similar to the average characteristic (normative) dimension.

Although the analyzed micrograins had the same normative size (F400), they differed significantly in terms of geometric parameters. And so, length distribution $l$ for 99C F400 micrograins has positive asymmetry and that of 98C F400 micrograins has negative asymmetry. Distributions of width b have negative asymmetry, and the surface area $A$ of micrograins - positive asymmetry. The distributions are flattened - they have a negative excess. The average shape factors differ slightly: $K=1.62$ for 98C F400 micrograins and $K=1.33$ for 99C F400 silicon carbide. More often, there are coniferous or dermoid -shaped grains (in the case of black silicon carbide).

\section{Summary}

Based on the research, several general conclusions can be drawn:

- The tested distributions most often have a negative asymmetry, especially in the case of larger abrasive micrograins (as well as relatively fine grains of BC F600 boron carbide). The exception was green silicon carbide 99C F400 with positive asymmetry.

- For the smallest grains, there are only slight deviations from the normative dimensions determined by the sedimentation method.

- The average values of the shape coefficients of the tested abrasive micrograins are similar and are in the range $K=1.33 \div 1.61$.

It should be emphasized that differences between individual micrograins with specific normative characteristics are affected by the abrasive production process, with crystallization conditions and the comminution process being of great importance.

The proposed method for measuring the size and shape of abrasive micrograins can be used to assess the quality of the abrasive before preparing a slurry or paste for technological lapping. The computerized microscopic method is relatively efficient and informative compared to sedimentation analysis.

Due to the possibility of occurrence of grain adhesions, the test should be carried out in conditions of adequate moisture content.

\section{REFERENCES}

[1] Bakoń A., Barylski A. „Preparaty na bazie nano- i mikrodiamentów do operacji docierania i polerowania". Mechanik. 8-9 (2014): 8-12.

[2] Bakoń A., Barylski A. „Ziarna i mikroziarna diamentowe. Rodzaje ścierniw i przykłady zastosowania”. Gdańsk: Wydawnictwo Politechniki Gdańskiej, 2017.

[3] Barylski A. „Obróbka powierzchni płaskich na docierarkach”. Gdańsk: Wydawnictwo Politechniki Gdańskiej, 2013.

[4] Barylski A. „Systemy automatycznej kontroli wymiarowej mikroziaren ściernych”. Diagnostyka. 3 (2006): 253-258. 
[5] Benea I.C. "Particle size and size distribution of superabrasive powder. Part 1". Diamond Tooling Journal. 3 (2010): 39-46.

[6] Benea I.C., Rosczyk B.R., Fitzgerald L.M. "Surface textured diamond particles - properties and applications". Diamond Tooling Journal. 3 (2011): 17-24.

[7] Bogatyreva G.P., Petasyuk G.A., Bazalii G.A., Shamraeva V.S. "On morphometric uniformity of diamond micro powder". J. Superhard Mater. 31 (2009): 126-134.

[8] Domozych M. „Analiza mikroskopowa kształtu i wymiarów ziaren ściernych”. Gdańsk: Politechnika Gdańska, Wydział Mechaniczny, 2016.

[9] Engis A. "The role of particles per carat in diamond tool behavior". Industrial Diamond Review. 2 (2003): $39-45$.

[10] Fletcher T., Gobena F., Romero V. "Diamond fixed abrasive lapping of brittle substrates". Industrial Diamond Review. 1 (2005): 25-31.

[11] Friedrich U. "Polished rolls make high-quality sheet steel shine". Industrial Diamond Review. 1 (2003): 16-17.

[12] Leavers V.F. "An active angularity factor for the characterization of abrasive particles". Wear. 239 (2000): 102-110.

[13] BIA information materials, Holtsville.

[14] CILAS information materials, Marcoussis.

[15] Computer Scanning Systems Sp. z o.o. information materials, Warszawa.

[16] Fritsch GmbH information materials, Idar-Oberstein.

[17] Gilson Company Inc. information materials Worthington.

[18] Horiba Ltd information materials, Kyoto.

[19] Hosokawa Alpine AG information materials, Augsburg.

[20] LECO Polska Sp. z o.o. information materials, Katowice.

[21] Malvern Instruments Ltd information materials, Malvern.

[22] Micromeritics information materials, Norcross.

[23] Microvision Instruments information materials, Evvy, Cadex.

[24] Particle Sizing Systems information materials, Santa Barbara.

[25] Rotex Inc. information materials, Cincinnati.

[26] Sympatec GmbH information materials, Clausthal-Zellerfeld.

[27] TST information materials, St. Paul.

[28] W.S. Tyler information materials, Mentor.

[29] Petasyuk G.A. "Interpretative and applied aspects of some morphological characteristics of superabrasive powder". J. Superhard Mater. 32 (2010): 128-139.

[30] Stachowiak G.W. "Particle angularity and relationship to abrasive and erosive wear". Wear. 241 (2000): 214-219. 